\title{
Berawirdkirina çîroka Hedlîlik Bedlîlik a bi Kurdî bi Gur û Heft Karikan a Birayên Grimm re
}

The Comparison of Bedlîlik and Hedlîlik of Kurdish and The Wolf and The Seven Young Kids of Grimm Brothers

\section{Hayreddin Kızıl', Veysel Tanrıkulu ${ }^{2}$}

\begin{abstract}
In this article, two tales were compared in terms of tale motifs. One of these tales, Hedlîlik and Bedlîlik was written in Kurmanji Kurdish and the other one, The Wolf and the Seven Young Kids was written in German language. Both tales are similar in terms of subjects and heroes. There are many variants of Hedlîlik and Bedlîlik tale. Here was preferred the variant compiled by M. Emin Bozarslan. The German tale was compiled by the Grimm Brothers. In the first chapter was examined " tales". In the second chapter are extracts and citations from the tales. In the third chapter, though, two tales were compared on the basis of tale motifs indicated by Stith Thompson.
\end{abstract}

Keywords: Tales, Hedlîlik and Bedlîlik, Brothers Grimm, The Wolf and the Seven Young Kids, Comparison

\section{Özet}

Bu makalede iki masal motifler yönündan karşılaştırılmıştır. Bu masallardan biri, Hedlîlik ve Bedlîlik, Kurmanc Kürtçesi, diğeri, Kurt ve Yedi Oğlak Almanca'dır. Her iki masal konu ve kahramanlar açısından da benzerdir. Hedlîlik ve Bedlîlik masalının bir çok varyantı mevcuttur. Burada M. Emin Bozarslan'ın derlediği varyant tercih edildi. Almanca masal ise Grim Kardeşler tarafindan derlenmiştir. Makalenin ilk bölümünde "masal” konusu incelendi. İkinci Bölümde masal metinleri mevcuttur. Üçüncü Bölümde ise Stith Thompson'un belirttiği motifler esas alınarak her iki masalın karşılaştırması yapıldı. Makale sonuç bölümü ile bitmektedir.

Anahtar Sözcükler: Masal, Hedlîlik ve Bedlîlik, Grimm Kardeşler, Kurt ve Yedi Oğlak, Karşılaştırma

Recommended citation:

Kızıl, H. \& Tanrikuluı, V. (2015). Berawirdkirina çîroka Hedlîlik Bedlîlik a bi Kurdî bi Gur û Heft Karikan a Birayên Grimm re [The Comparison of Bedlîlik and Hedlîlik of Kurdish and The Wolf and The Seven Young Kids of Grimm Brothers]. International Journal of Kurdish Studies 1 (2), pp.70 - 85 .

\footnotetext{
${ }^{1}$ Corresponding Author: Asst. Prof. Dr. Kurdish Department, Dicle University, Diyarbakir, Turkey. E-mail: hkhayreddin@gmail.com

${ }^{2}$ MA student, Institute of Social Sciences, Department of Kurdish Language and Culture, Dicle University, Diyarbakir, Turkey.
} 


\section{DESTPÊK}

Çi çîrok çi stran çi zugotinok be, bê guman hemû zargotin an jî vegotinên gelerî girîng in. Ji po pêşketina çanda Kurdan xebatên akademîk derheqê van vegotinên gelerî de jî girîng e. Lê dema em li xebatên di vê warê de dinêrin em tenê berhevkirina wan dibînin. Bi keda xwemxwirên lêkolîner û berhevkarên hêja gelek vegotinên gelêrî ji wendabûnê xelas bûn.

Lê tenê berhevkirin nabe ji bil van xebatan berawerdkirin û muqayeseyên çîrokan bi çandên din re, analîza wan û ji alî zimên ve nirxandina wan jî divê. Di vê gotarê de me jî berawirdkirina du çîrokan hilbijart. Mijara me yek bi Kurdiya Kurmancî yek jî bi Elmani berawirdkirina du çirokan e. Çîroka bi Elmanî ya bi navê Bizin û 7 Karikên wê ji alî Birayên Grimm ve çîroka bi Kurdî ya bi navê Hedlîlik û Bedlîlik ji alî M. Emin Bozarslan ve hatiye komkirin. Xebata Birayên Grîmm a li ser çîrokan li her derê cihanê tê zanîn û naskirin. Lê ne çanda Kurdan ne jî zargotina wan -wek li jor jî me nivîsî ji ber kêmbûna xebatên di vî warî de- nayê zanîn û nehatiye lêkolînkirin. Gotara me jî ji bo xebateke berawirdkirinê mînakek e. Xebatên me yên di vî warî de wê bidomin.

Beriya gotarê em dixwazin li ser mijarekê çend tiştan bibêjin: Di zimanê Îngilizî de ji bo çîrok "tale", Fransewî de "conte", Tirkî de "masal", Erebî de "mesel”, Elmanî de jî "machen" tê bi kar anîn. Di Kurdiya kurmancî de derhaqa cureya vê vegotinê de gelek peyv hene. Çirok, çirçironik, dastan, xebiroşk, çêrçerok, çîronk, çîvanok, qewatî, be ser hat,meselok,xeberoşk, çîrvanok, çîrçîrok,serborî, metalok, kurteçîrok, xemisok, mesel, serpêhatî, hîkaye hwd. (Mukrîyanî, 2010:283; Bozarslan, bnr Navê Pirtûka wî Meselokên Lawiran e, 1999; Bedirxan 2009:98; Pertev, 2009:87; Saadallah, 2000:1238; Kurmancî, 2010:266.)

Zêdebûna peyvan ji bo tale'yê di Kurdiya Kurmancî de tevlîhevîyekê jî tîne. Lê bes ev mijar ne têne ji bo kurmancî ji bo zimanên din jî heye. Wek mînak di Tirkî de nîqaşa masal an jî hîkaye, hê jî berdewam e (Bnr Sakaoglu, 1999: 2). Ji ber ku di pirtûkên berhevkirinê û di berhemên lêkolînan ên Kurdiya Kurmancî de bi piranî 'çîrok' hatiye bikaranîn (Firat Cewerî, “Antolojîya Çîrokên Kurdî”; Mehmet Öncü,“Çîrokên Kurdan 1-2”; Riza Çolpan, Çîrokên Gelî; Ramazan Pertev, "Çîrok û Zarok"; Eslîxan Yildirim, "Herdem Cîwanê -Çîrokên Gelerî-) em ê jî di vê gotarê de peyva çîrokê di dewsa "tale" Îngilizî û "machen" Elmanî de bikar bînin.

\section{1. Çîrok}

Ji bo fêmkirina mijarekê pênasekirina wê girîng e ji ber vê divê em pêşî li ser pênaseya çîrokê rawestin. Çi li nav Kurdan çi jî li cîhanê pênasekirineke hevpar ji bo çîrokê çênebûye. Her nivîskar, her berhevkar û lekolîner li gorî xwe çîrok pênase kiriye.

Li gorî Rohat Alakom, "Çîrok beşeke folkklorê ye, nivîskarên wan ne kişf in, gel bi xwe ev berhem afirandine” (Alakom, 2002:11), Ramazan Pertev jî ji bo çîrokê, "cureyek ji vegotinên gelêrî nin ku tê de cih didin serborî $\hat{u}$ lêhengên derasayî $\hat{u}$ mijara wan xeyalî $\hat{u}$ bi devkî belavbûyî nin." dibêje (Pertev, 2009: 87-89). 
Kenneth W. Clarck û hevsera wî Mary W. Clark ji bo pênasekirina çîrokê nerîna xwe wisa par ve dikin:

"Pexşanên ku serkeftina lehengên ji rêzê û derasayîye dihundirînin. Ev leheng ji alî sihud û navdarbûnê ve di cihaneke serastiyê de ku cihana karakterên derasayî û cinawiran e, bi ser dikevin" (Sakaoğlu, 1999:3)

Ansîklopediya folklorê ya herî navdar (Funk and Wagnalls Standart Dictionary of Folklore) pênasekirina çîrokê hinek berfireh dike:

"Çîrokên gelerî (folktale) di Îngilîzî de têgehek gelek berfireh e. Ji bo penasekirineke teqez kes hewl nedaye. Lê belê çîrok, peyveke giştî ya aîdê hemû cureyên vegotinên kevneşopîyê ye û li der hatiye hiştin.” (Sakaoglu, 1999:3)

Çîrok di dîroka mirovahiyê de her çiqas gelek kevin bibe jî xebatên akademik li ser çîrokê piştî du birayên Elman Birayên Grimm pêş de çûn. Birayên Grîmm Jacop Ludwing Grimm (1785-1863) û Wilhelm Karl Grimm (1786-1859) her du bira gundên Elmanya yê gerîyan (Aykanat, 2013:170) û xeberoşk, efsane û menqibeyên bi Elmanî berhev kirin û bi navê Kinder und Husmarchen (Çîrokên ji bo Zarok û Maliyan) weşandin (Yavuz, 2002:15). Beriya Birayên Grîmm li Elmanyayê nîqaşên ekola rasyonalîzm û îrrasyonalîzmê hebû. Piştî van nîqaşan romantîzm bi pêş ket, kesên ku di bandora romantîzmê de man dest bi berhevkirina helbestên gelerî bi taybetî jî çîrokan kir (Aykanat, 2013:170). Xebatên Birayên Grîmm di vî alî de pêşengtî kir û xebatên wan wekî ilhama ekola romantîzma Elmanî tên qebul kirin (Yildirim, Pertev û Aslan, 2013: 20).

Mijarên sereke û bala lekolînvanên çîrokan dikşîne çavkanîya çîrokan e. Ango çîrok di diroka mirovahiyê de kengê dest pê kiriye û çawa li cihanê belav bûne? Dema nîqaşa çavkanîyên çîrokê derdikeve bi gelemperî sê heyam û li ser her heyam jî çend navên girîng derdikeve pêşîya me. Li ser vê mijarê senifandina ya Gedeon Huet wisa ye: "Nêrîna Beriya Dîrokê (Dibistana Mîtolojî), Nêrîna Dîrokî (Dibistana Hîndolojî), Nêrîna Etnografîg Nijadnasî- (Dibistana Antropoloji)"(ji bo agahiyên berfireh bnr. Sakaoglu, 1999:5-7).

Taybetmendiya ekola Nêrîna Beriya Dîrokê wisa ye: Mirov gere koka çîrokê li mîtolojîya Hîndan (Veda'yan) bigere. Dema ku xêzina zimanê Sanskritî û Hînt-Ewrûpa derket pişt re ev nêrîn jî derket hole. Parastvanên vê nerînê G.Grimm (1819) û Dasent(1859), Muller û Sir George Cox in. Ekola Nêrîna Dîrokî jî mîna nêrîna yekem, Hindîstanê wekî çavkanîyek qebul dike. Lê li gorî nûnerê vê nêrînê Sylvestre de Sacy, çavkanîya çîrokan ne Veda ne, Sacy di dewsa Veda'yan de Pançatantrayê nîşan dide. (Sakaoglu, 1999: 5-7). Theodor Benfey, Pançatantrayê (Pênç Pirtûk), di sala 1859an de wergerand Elmanî û weşand. Benfey li wir bal dikşîne li ser nêzikahîya çîrokên Hîndûyî, Ewropeyî û yên derveyî Ewropeyî. Li ser van şibandina jî navê teorîya xwe "deynwergirtina çîrokan” dide. Li gorî Benfey, Rojava gelek çîrok ji Rojhilatê deyn girtine. (Yildirim, Pertev û Aslan, 2013:61).

Gellek rexne, li ser fikrên dibistana Hîndolojî hatin kirin. Piştî van rexneyan fikrek nû derket hole ev jî nêrîna antropolojî bû. Nûnerên vê nêrînê Andrew Lang, Edward Tylor û M. Lennan in û her sê jî etnografin. Li gorî wan çîrok ne ya bermahîyên mîtolojî ne yên jîyana 
şareza ne. Li gorî Tylor çîrok di çêkirina têgînên der bare yê jiyana rojaneyî, olî û helbestkî de dişibin hev. Tylor vê yekê bi hevparîya siruşt, psîkolojî û ramana mirovan rave dike. Yanî riyên pêşketinê yên çanda mirovahiyê hevpar in. (Yildirim, Pertev û Aslan, 2013:43)

Andrew Lang(1844-1912) jî; mijara çavkanîya çîrokan ya ku Hindistanê derdixîne pêş napejirîne. Lang, di çîrokan de li ser fikrên hov disekine û dibêje ku çîrok di demek pir kevn de avabûne. Şibîna çîrokan bi hevdû re girêdayî nîn in û ji hev serbixwe ne. Mirovên ku her çîqas asta çanda wan cûda be jî bawerî û gerdîşî wan mîna hevdû ne. Çîrok jî mîna wan, bi pêşketina çandê rastên hev dibin û di encamê de çîrokên manend jî derdikevin holê. (Sakaoglu, 1999:9)

\subsection{Giringîya Çîrokan ji bo Kurdan}

Wekî li jor jî hat nivîsîn di Kurdî de li ser navkirina "çîrok"ê nêzikê 15 nav tên bikaranîn. Bê guman sedemên pirbûna navan hene. Bo me sedema yekemîn kêmbûyîna berhemên nivîskî ne. Ji ber ku nivîs di nava gelê Kurd de zêde nehatiye bikaranîn. Gelê kurd çand, dîrok, tecrubeyên xwe bi riya devkî û bi çîrokan gihandîyê roja me ya îro. Em bi riya wan berhaman li ser dîrok, mîtolojî û destanên kurdan agahî digrin. Sedemeke dinê jî dîsa bo me, çîrok bi gelemperî ji bo perwerdekirina zarokan hatiye bikaranîn. Vêca ji bo hezkirin û pêşirînkirina zarokan ji bo çîrokê navên balkêş wekî çirçîrok, çîvanok, çêrçerok, çîronk, çîvanok û hwd hatine û tên bikaranîn.

Rohat Alakom di derheqê vê mijarê wisa dibêje

"Ev berhem şîretan li me dikin, rê nîşanî me didin û me di nav fantazîyên rengîn de dihêlin. Fantezi, xewn, xewnerojên sedsalan di nav van çîrokan de her çûne dewlemend bûne. Beşek jî wan bi rastîyên jîyînê ve gihiştine hev, ji aliyê mirovan de têgihiştina jîyînê zêdetir hêsantir kirine. Di wî warî de çîrokên Kurdî gelekê hînkar û şîretkar in."(Alakom, 2002:11)

Li cem kurdan yek ji sedema taybetîyên çîrokên gelerî jî erdnigarî ye. Îzady di pirtûka xwe de derheqa sedema zivistanên dijwar û tekilîya wêbi çîrokan re wisa nîşan dide "firehtirîn beşa çîrokên gelerî yên kurd, em dikarin di bin navê "Kurdish winter storiesçîrokên zivistanê yên Kurdan” de berhev bikin. Lewra ev çîrok bi gelemperî di şevên dirêj û sar û xetere yên zivistanên Kurdan de tê vegotin. Ev çîrok behsa serkeftin û têkçûnên lehengan dikin. Di van çîrokan de, ji bo guhdarvanan di dawiyê de gelek gotinên bi şîret, bi mesaj û rê û rêbaz hene ku mirov bi wan xwe ji şertên demsala zivistanê diparêzin. (Izady, 1992: 239)

Çîrokên gelerî li ser netewbûyîna Kurdan jî cihekî girîng digre. Komelaya Kurd ji bo Belavkirina Zanînê û Weşanan (Kürt Tamim-i Maarif ve Neşriyat Cemiyeti) di beyanameya xwe de giringî daye li ser xebatên folklorîk û wekî xalek jî di benda/xala heftemîn de qala berhevkirina çîrokên gelêrî kiriye (Yildirim, Pertev û Aslan, 2013:61). 


\section{2. Çirokên Hedlîlik î Bedlîlik a bi Kurmancî û Gurû Heft Karikan a Bi Elmanî}

Li ber destê me çar varyantên çîroka Hedlîlik û Bedlîlik hene.Sê ji van çîrokan Mamoste Hilmi Akyol berhevkirine. Ji van yekê navê wê Bizin û Gur (Xezalok û Delalok) e. Mamoste ev çîrok li herêma Sêrtê berhev kiriye û di sala 2010an de, di pirtûkekê xwe -Kew û Kewê- de weşandiye(Akyol, 2010: 13-14). Her du yên din jî dîsa ji alî Akyol ve li herêma Amedê hatiye komkirin. Navê yek ji van navê çirokan Heblûlik û Ceblûlik a din jî Şengê û Pengê ye. Her du çîrok jî ji alî Akyol ve heta niha nehatiye weşandin.

Varyanta me ya çaremîn a di pirtûkekê M. Emîn Bozarslan de heye. Bozarslan, di pirtûka xwe ya bi navê Meselokên Lawiran de ev çîrok bi navê Hedlîlik û Bedlîlik weşandiye (Bozarslan, 1999:61-69). Ji ber ku varyanta Akyol a bi navê Kew û Kewê kurt e û varyantên din jî nehatine weşandin me varyanta Bozarslan hilbijart. Dîsa jî ji bil varyanta Bozarslan em ê ji varyantên din jî sûd wergirin.

Çiroka duyemîn ango“"Gur û Heft Karikan” resen bi Elmanî ye. Me ev çîrok ji Tirkîyê wergarand Kurmancî. Me Elmanî û Kurmancîya çîrokê ji wergêr Mehmet Aksakal re şand. Piştî çend rastkirina çîrokê me di gotara xwe de cih da. Li ser înternetê wergerekê Kurmancî din jî çiroka Gur û Heft Karikan heye (http://e-weje.com/birayen-grimm-u-ciroka-gur-u-heftkarik/ -dîroka lênêrînê 08/08/2015-)

\subsection{Hedlîlik û Bedlîlik}

Hebû tunebû carek ji caran, rehme li dê û bavên guhdaran, xeyn ji cendirme û tehsildaran.

Bizinek û du karên wê hebûn. Navê yekê ji wan her du karan "Hedlîlik" bû, navê ya dî jî "Bedlîlik" bû. Bizinê her du karên xwe jî pirr û pirr dievandin. Karik jî, yek ji yekê xweşiktir û şîrîntir bûn. Dema tav derdiket, her du diçûn ser mêrga hemberê koza xwe û bi hev ra dileystin. Geh çindik didan xwe û li ser mêrgê dibezîyan, geh jî bi seriyan li hev dixistin. Kesên ku ew didîtin digotin qey du qulatên zêr in.

Diya wan rojê sê-çar car diçû li ser mêrgan diçêriya, guhanê wê tijî şîr dibû, paşê vedigeriya kozê. Hedlîlik û Bedlîlikê ku çav didan diya xwe, ji kêfan lotik didan xwe û xwe bilind dikirin li erdê dixistin. Paşê jî bi dilbijokî guhanê diya xwe dimêtîn, heta ku têra xwe şîr dixwarin.

Rojek ji rojan, diya wan dîsa çû çêrê. Mîna hemî caran, berî ku ji kozê derkeve şîret li Hedlîlik û Bedlîlikê kir û got:

-Karên min ên xweşdivî, heta ez neyêm hun derê kozê ji kesek ra venekin haaa! Hin kes bên ji we ra bêjin "Derî vekin" jî, divê hun bi wan nexapin û derî venekin. Dema ez bêm, ezê wek hemî caran lingê xwe di binê derî ra dirêjê hundir bikim. Ku we lingê min dît, bizanin ku ez im û derî vekin. Yan na, hun derî ji kesekî dî ra venekin haaa!

Hedlîlik û Bedlîlikê guhdarîya diya xwe kirin û şîreta wê di hişê xwe da girtin. Diya wan xatir ji wan xwest û çû. Wan jî derê kozê li pey wê girt. Paşê her du jî razan. 
Ewxu di wê demê da gurek jî li wan doran digeriya. Qasek paşê çavê gur bi koza Hedlîlik û Bedlîlikê ket. Tavil bêhn girt ku her du karik di hundir da ne. Çû ber derê kozê, dît ku derî girtîye. Xwest ku Hedlîlik û Bedlîlikê bixapîne. Dengê xwe kir mîna dengê bizinek û meîn kir, got: "me-e-e-e-e-e"

Hedlîlik û Bedlîlik bi dengê wî ji xewa xwe hişyar bûn. Paşê gur dîsa dengê xwe kir wek dengê bizinek û deng li wan kir, got:

-Karikno, diya we li kêderê ye?

Hedlîlik û Bedlîlikê nedizanîn ku ew gur e deng li wan dike. Gotin qey bizineka dî ye li karên xwe digere. Bi devek bersiv dan û gotin:

-Diya me çûye çêrê ji me ra şîr tîne.

Gur dîsa dengê xwe kir wek dengê bizinek û pirsî, got:

Navê we çi ye, karikên xweşik?

Karikan got:

-Navê me Hedlîlik û Bedlîlik e.

Gur xatir ji wan xwest û ji ber kozê çû. Nedixwest ku Hedlîlik û Bedlîlikê têxe gumanan. Dixwest wan xafil bike û bi xapê derê kozê bi wan bide vekirin.

Qasek gerîya, dîsa çû ber derê kozê, wek cara berê dengê xwe kir wek dengê bizinek û deng li wan kir, got:

- Hedlîlikaaaa'm, Bedlîlikaaa'm!

Derî vekiiiiin ji dayîka xwe raaa

Çêra şînaaa li ber didanaaaaan

Şîrê terêêêêê li guhanaaaaan.

Hedlîlik û Bedlîlikê li hev nihêrtin. Bawer nekirin ku ew diya wan e hatiye ber derî. Lewra şîreta ku diya wan li wan kiribû û gotibû 'Ez'ê wek hemî caran lingê xwe di binê derî ra dirêjê hundir bikim", ew şîret di bîra wan da bû. Gotin:

-Tu derew dikî tu ne diya me yî

Gur dest bi fenan kir û got:

Eman yeman, çawa ez ne diya we me! Ku ez ne diya we bûma çima min ê bigota "Ji min ra derî vekin!"

Her du karikan got:

-Ka lingê xwe nîşanê me bide, em bibînin. Hingê em ê bizanin ku tu diya me yî, yan na. 
Gur lingê xwe di binê derê kozê ra dirêjê hundir kir. Hedlîlik û Bedlîlikê dîtin ku rengê lingê wî gewr e. Lê belê rengê lingê diya wan reş bû. Wan jî xwest ku gur bixapînin.

Gotin:

-Rengê lingê diya me sor bû. Tu ne diya me yî. Em ji te ra derî venakin.

Gur hêdîka lingê xwe bi paş ve kişand. Têgihişt ku karik xasûk in. Di dilê xwe da got "Gelo ez çawa bikim ku keys li van karikan bînim û wan bixwim? Ji alîyek ve jî zimanê xwe li dora devê xwe dixist û tama devê xwe xweş dikir. Paşê çû, li axdanek xwe di nava soringê da gevizand, heta ku pirça wî bi carek sor bû. Hingê xwe bi xwe got "Temam, vêca ez ê bikarim wan her du karikan bixapînim û bixwim." Ji kêfan dûvê xwe hejand û dîsa ber bi kozê çû. Dema gîha ber derî dîsa dengê xwe kir mîna dengê bizinek û deng li her du karikan kir, got:

- Hedlîlikaaaa'm, Bedlîlikaaa'm!

Derî vekiiiiin ji dayîka xwe raaa

Çêra şînaaa li ber didanaaaaan

Şîrê terêêêêê li guhanaaaaan.

Karikan dîsa bawer nekir ku ew diya wan e. Gotin:

Tu derew dikî tu ne diya me yî.

Gur dîsa dest bi dek û dolabên xwe kir û got:

-Ma hun dîn bûne çawa ez ne diya we me! Ma ku diya we nebe, kî tê ji we ra dibêje "Ka ji min ra derî vekin” wella ez diya weme, bîlla ez diya we me.

Hedlîlik û Bedlîlikê gotin:

-Madem tu diya me yî ka lingê xwe di binê derî ra dirêjê hundir bike em bibînin.

Gur lingê xwe di binê derî ra dirêjê hundir kir. Karikan dît ku rengê wî sor e. Zanîn ku ne diya wan e. Jê ra gotin:

-Tu derew dikî, tu dixwazî me bixapînî. Tu ne diya me yî. Lingê diya me reş bû, lingê te sor e. Em ji te ra derî venakin.

Gur dîsa lingê xwe bi paş ve kişand û kor-poşman vegeriya. Dîsa tiştek bi devê wî neket. Xwe bi xwe got "Gelo ez çawa bikim ku van her du karikên mizawir bavêjim devê xwe û bi noşîcanî bixwim?"

Paşê rabû çû cîyekî reşik û xwe di reşikê da gevizand, heta ku laşê wî û pirça wî gişt reş bûn. Paşê xwe da ber tavê ziwa kir û dîsa berê xwe da koza Hedlîlik û Bedlîlikê. Lingê xwe di binê derê kozê ra dirêjê hundir kir, dengê xwe kir wek dengê bizinek û mîna berê deng li her du karikan kir, got:

- Hedlîlikaaaa'm, Bedlîlikaaa'm!

Derî vekiiiiin ji dayîka xwe raaa

Çêra şînaaa li ber didanaaaaan 
Şîrê terêêêêê li guhanaaaaan.

Hedlîlik û Bedlîlikê vêca ku lingê wî nihêrtin, dîtin ku erê, lingê wî wek lingê diya wan reş e. Li ser wê yekê jê bawer kirin û gotin qey diya wan e ji çêrê vegeriyaye û dixwaze wan bi guhanê xwe bimijîne. Kêfa wan hat û bi wê kêfê rabûn derî vekirin. Derî çawa vebû, gur hema ji nîşka ve qavz da û xwe avêt ser wan. Berê Hedlîlik, paşê jî Bedlîlik avêt devê xwe, her du jî daqurtandin û xwarin. Paşê çû ser kanîyeka nêzê kozê û têra xwe av vexwar. Zikê wî bi her du karikan û bi avê nepixî, bû mîna dawilek û ma. Vêca çû, li siya dareka nêzê kanîyê vezeliya û raket.

Qasek paşê diya Hedlîlik û Bedlîlikê ji çêrê vegeriya. Dema gîha ber derê kozê, dît ku çi bîbîne! Bala xwe dayê ku derî vekirî ye, her du karik jî ne li hundir in. Di dîlê xwe da got "Heywax û heywax, hemin tiştek hatiye serê Hedlîlik û Bedlîlika min".

Paşê dest pê kir li wan geriya. Ha li vir, ha li wir, hew dît ku gurek wa ye li siya darek raketî ye, zikê wî jî mîna dawilek nepixî ye. Di dilê xwe da got "Hebe tunebe vî gurî her du karikên min xwarine."

Paşê rabû çû ber kevirekî mezin, her du q1loçên xwe di kevir da heşilandin, heta ku serên wan tûj bûn, bûn mîna serên du nişteran. Vêca berê xwe da binê wê dara ku gur di sîya wê da raketî bû. Dizîka, hêdî hêdî çû û xwe gihand ber gur. Dît ku erêêêe, gur di xeweka kûr da ye û "pixxxxîn" a wî ye. Bizinê hema ji nîşka ve serê qiloçekî xwe yê tûj, heta ku hêza wê hebû li zikê gur xist û zikê wî qelaşt.

Çawa zikê gur qelişî, Hedlîlik û Bedlîlikê hema lotik dan xwe û ji zikê wî derketin der, bi lez û bez xwe avêtin ber diya xwe. Kêfa wan hat ku gîhîştin. Diya wan guhanê xwe yê tijî şîr avêt devên wan û ew mijandin. (Bozarslan, 1999:61-69)

\section{2. Çîroka Gur û Heft Karikan}

Hebû tune bû, heft karikên bizinekî pîr hebûne. Dayîk çawa zarokên xwe hezdikin wê jî wisa ji çêlikên xwe hezdikir. Rojek ji nav rojan ev bizin ji bo karikên xwe re xwarinê bibîne û bîne, beriya biçe daristanê karikên xwe li derdora xwe kom dike û dibêje.

-Zarokên min ên delal, ez diçim daristanê. Xwe ji gur biparêzin. Heke gur têkeve mala meêw ê we parî parî bixwe. Ev bênamus (nemerd) pir caran dikeve hezar şeklî, lê hûn bi hêsan dikarin wî ji ji dengê wî yê stûr û lingên wî yên reş nasbikin.

Karikên biçûk:

-Dayika me yê delal, bila çavên te li paş nemînin... Bi xêr û xweşî biçe û bi xweşî were... Em êxwe biparêzin. Bizin dimare û bi dilekî aram dikeve rê. Hîn pir dem li ser çûyîna bizinê çênebûye ku kesek li tê deriyê wan dixe û dibêje

-Zarokên min ên delal, derî vekin. Dayika we hat, min ji we re hîn tişt anîn.

Lê karik dengê gur ê stûr nasdikin û ji hundir:

-Tu ne dayîka me yî. Dengê dayîka me him zirave him jî şêrîne. Dengê te stûre. Tu gurî! 
Ser vê gur diçe dikanê, tebeşîrek gir dikire û wê dixwe. Bi vî awayî dengê xwe zirav dike. Dawiyê dizivire û dîsa li derî dixe. Dibêje:

-Zarokên min ên delal, derî vekin, dayika we hat û ji we re ji daristanê gelek tişt anine." Gur lingên xwe yên reş û qîr dispêre pacê. Dema karikan lîngên wî yên reş û qîr dibînin dîsa qîr dikin:

-Em derî ji te re venakin. Lingên dayika me wekî yên te nereş in. Tu gurî!

Gur dîsa dizivire û diçe firinekê û ji nanpêj re dibêje:

-Min lingên xwe li kevirekî xist, tu dikarî piçek hevîr lê bidî?

Firinkar hevîr li lingên gur dide. Vê care gur bazdide ba aşvan. Dibêje:

-Hinek ard li ser lingên min pê werke:

Aşvan ji xwe re dibêje:

-“Gur dîsa dike hinekî bixapîne” û naxwaze ar bidê. Lê gur:

-Heke tu gotinên min neynî cih ez ê te bixwim û qîr kiriye. Wê demê aşvan tirsiyaye û di cih de kulmek ard li ser lingên gur direşîne. Ji xwe hemû mirov wisa ne!

Piştê, wê bênamusê gur cara sisêyan diçe malê û li derî dide, dibêje:

-"Zarokên min ên delal derî vekin, dayika we yê delal hat malê, ji bo we ji daristanê tiştek anîye" karik qîr dikin, dibêjin:

-Pêşî lingên xwe nîşane (ray) me bide. Ku em fehmbikin tu dayîka me yî delal î.

Gur lingên xwe dispêre pacê. Dema karik dibînin lingên gur spîye bawer dikin ku wî çi gotiye rast e ji wî re derî vedikin...

Lê çi dibînin? Yê ku hatiye gur e. Karik nizanin wê çi bikin û cihekî ji bo xwe veşêrin digerin. Yek ji wan direve bin masê. Yê duyem dikeve nav nivînan. Yê seyem dikeve hundire sobê. Yê çarem di metbaxê (pêjgeh) de xwe vedişêre. Yê pêncem dolabê. Yê şeşem dikeve binê sepeta cilan. Yê heftem jî dikeve hindirê saeta dîwêr.

Lê gur bi lez hemêyan yek bi yek digre. Hew yê heftem ku ketiye hundirê saetê nabîne. Ji ber zikê xwe têr kiriye tew li wê nagere û diçe li ser çêreyek hêşinahî li bin darekê xwe li ser piştê vedizelîne û radizê.

Piştî demek kurt dayika bizin vedigere malê. Hahoo! Çi dî ye? Deriyê malê heta dawiyê vekirî ye. Mase, sendelî hemû li nava hev ketine. Sepeta cila perçe perçe bûye. Balîf û lihêf, nivîn tev li erdê ne. Dayika bizin zarokên xwe digere lê li tu derê nabîne. Yek bi yek bi navê wan gazî wan dike, le ji kesekî bersiv nastîne. Herî dawî bi navê karika xwe yî dawî gazî dike. Vê carê dengekî zirav bihîstîye.

Ez di nav saeta dîwêr de me dayê can!

Bizin zaroka xwe ji wir derdixe. Karika biçûk qala hatina gur û xwarina hemû xwişk û birayên xwe dike. Hûn jî pê derdixin ku dayika bizin çîqas hêstirên xwe ji bo zarokên xwe yên jar dibarîne. Herî dawî bi vê janê derdikeve derve. Karika wê ya biçûk jî pê re ye. 
Dema digêjin cihê çêreyê gur di binê darê da dibînin.Ewqas bi deng razaye ku ji dengê wî şaxên darê dilerize. Dayika bizin, demek dirêj gur temaşe dike. Dibîne ku di zikê gur de hinek tişt dilivin. Bizin di hundirê xwe de gotîye:

Yêzdane dilovan! Gur karikên min ên ji xwe re kiribû şîv dibe ku hîn zindî bin?

Li ser vê yekê karika biçûk diçe malê û bi xwe re meqes, derzî û ta tîne. Dayika bizin zikê gur diqelişîne. Hîn qulukek biçûk venebû ku karikekî serê xwe derxist derve. Dema hinekî din diqelişîne her şeş karikên wê pişt hev derdikevin. Hemû jî zindî bûn, qet tiştek bi wan ne hatibu. Tu nabê gurê çavbirçî ew necutine hema ew daqurtandine.

Hela dilxweşiya wê demê hun bifikirin! Hemû xwe davêjin stûyê dayika xwe yên delal. Dayika bizin dibêje:

-De hadî îja biçin hinek kevir kom bikin û bînin... Berî ku ev bêîmanê gur şiyar bibe em zikê wî tijî bikin.

Heft karik bi lez hinek kevir tînin û zikê gur tijî dikin. Dawî jî dayika bizin bi lez çermê wî didirû. Di vê navberê de gur hay ji çi tiştî çênebûye û ji cihê xwe nelivyaye. Piştî gur têr radizê radibe ser lingan. Ji ber zikê wî bi kevir tije ye gelek tî dibe. Dixwaze here ser çemekî ku avê vexwe. Dema dimeşe kevirê zikê wî li hev dikevin. Li ser vê yekê gur:

Hela vê karê binêrin!

Dengê çi ji zikê min tê?

Şeş karikên min daqurtîbû.

Tu dibê qey bûye kevir! Dibêje. Dema diçe li ser çem ji bo avê vexwe xwe daqul dike. Lê ji ber giraniya kevirê di zikê wî de ketiye nava çem û bi qîre qîr difetise û diçe. Karikan dema ku dît gur fetisî bi bazdan hatin û wan got:

-Gur mir! Gur mir! Dîqirin û bi dayika xwe re bi kêf û coş ber çem çindika didin. (J. û W. Grimms, 1999: 29-30)

\section{Berawirdkirina Herdu Çîrokan}

Ji xwîneran re jî diyar e ku her du çîrok di gelek cihan de dişibin hev û em karin bibêjin ku kopyaya hevûdu ne. Şibandin hîn di bikaranîna peyva çîrokê de destpê dike. Di zimanê Elmanî de ji bo çîrok peyva "märchen" tê bikar anîn. Ev peyv ji "maere" tê, wateya "maere" jî xeber e (Panzer, 1973:84, veguhêzer Coşan, 2001:1). Li gelek deverên Kurdistanê ji bo çîrok peyva xeberoşk (Farqînî, 2007:737) jî tê bikaranîn. Ev peyv jî ji koka“xeber”ê tê. Di her du zimanan de jî peyv - peyvên maere û xeberoşk- ji wateya xeberê hatine dariştin.

Dema em li çîrokan dinêrin herikandina bûyer, karakterên sereke, cihê bûyerê, hetta binavkirina çîrokan jî yek e. Her du çîrok jî navên xwe ji karakterên çîrokê sendine. Çîroka bi Elmanî Gur û Heft Bizine. A Kurdiya Kurmancî jî Hedlîlik û Bedlîlik e. Di varyantên Hedlîlik û Bedlîlik de binavkirin cuda be jî dîsa karakterên çîrokê navê xwe dane çîrokê. Mînak: Heblûlik û Ceblûlik (Amed), Xezalok û Delalok (Bizin û Gur) (Sêrt), Şengê û Pengê (AmedHazro). 
Di vê beşê de em ê berawirdkirina her du çîrokan li gorî "Kataloga Motifên Çîrokan ya Navnetewî" ya Stith Thompson bikin. Thompson ev motîf di pirtûka xwe ya di Motif Index of Folk-Literature de tasnîf kirine. Thompson "motîf” ê wisa pênase dike: "hemanê herî piçûk a çîrokê ye û ji demên berê heta îro dikare bijî." Lêgerînerê çîrokê ya Alman Max Lûthî jî motîfê wisa pênase dike: "hêmanê herî biçûk a çîrokê ye ku xwe di nav kevneşopîyan de parastiye" (Sakaoglu, 1999:15). Ali Berat Alptekin di "motîf'ê de derasayiyê dixwaze, li gorî wî ji bo tiştek bibe motîf divê derasayî be (Alptekîn, 1997:297).

Ji ber ku heya niha derheqên motîfan de, di Kurdî de xebat nehatiye kirin pêşî em ê Kataloga Motîfên Çîrokan ya Stith Thompson bidin. Thompson ji bo senifandina motîfan ji her motîfekê re tîpek diyar kiriye û wisa rêz kiriye:
A. Ajalên Mîtolojîk
B. Ajal
C. Qedexe Kirin
Ç. Sêhr
D. Mirin
E. Derasayî
F. Hûtan
G. Ezmûnan
H. Biaqil û Xêvok
I. Xapandin
Î. Tersgerîna/Berovajîbûna Qederê (Reersals of Fortune)
J. Destnîşankirina Dahatûyê (Ordaining the Future)
K. Sihûd û Qeder
L. Civat
M. Xelat û Ceza
N. Dîl û Firaran
O. Zilma Neasayî
P. Zewac
Q. Xwezaya Jîyanê
R. Ol
S. Taybetmendiya Karakteran
Ş. Qerf
T. Komên Motîfên Curbecur (Alptekîn, 1997:299-300;
http://www.ruthenia.ru/folklore/thompson/05/08/2015) 
Li gorî van motîfan dema em her du çîrokan bidin berhev em ê di gelek cihan de şibînan. Ji vê şûn de jî em ê li ser motîfên li jorê berawirdkirina her du çîrokan bikin.

Ajal

Li gorî senifandina cureyên çîrokan a Thompsonê "Kataloga Çîroka ya Navnetewî" her du çîrok jî cureya çîroka ajalan e. (Yavuz, 2002: 17). Di her dû çîrokan de jî karakterên sereke ajal in -bizin, karik, gur-. Ev motîf bi tîpa Byê tê nîşandayîn.

Di varyantên çîroka Hedlîlik û Bedlîlik da wekî karakterekî alîkar rovî jî dikeve çîrokê. Bizin dema karikên xwe digere peşî diçe li cem rovî û karikên xweji wî dipirse.

Dema em ji bo temsîlkirina karakteran binêrin, de her du çîrokan de gur temsîlîyata nebaşiyêye. Armanca wî eve ku karikan bixwe. Nebaşiya gur ne tenêdi vê çîrokê de, di nav biwêjên Kurdî da jî heye. Wekî mînak em dibêjin "hevalê gur e" an jî "Gava mirov gur be rojên bi mij pir in”. Dîsa çavbirçîtîya gur jî navdar e. Gur dema êrişî pezekî bike, heke ew pez sed heb bin jî̀, wan her sedan jî dikuje lê ji wan tenê yekî dixwe (Ronahî, 2009:44).Di çîrokênElmanî de jî gur sembola nebaşiyê ye. Wek mînak, çîroka keça kum sor.

Di her du çîrokan de jî karik temsîlîyata masumîyetêne, ji ber ku karik biçûkin û benda diya xwene ku were wan têr bike. Dayîk jî di peywira xwe ya esasî xwedîkirina karikên xwe û berdewamkirina jiyana wan de têdikoşe.

\section{Qedexekirin}

Ev motîf jî bi tîpa Cyê di lîsteyê da cî digre. Di her du çîrokan da jî derî vekirin ji bo gûr her wekî ajalên xirab tê qedexekirin. Derî li vir wekî sînorek hatiye nîşandan. Hundir ciyê ewlehiyê ye. Lê li der xetere hene. Ji ber wê derî vekirin ji alîyê dayika wan hatiye qedexekirin. Karik ji bo parastina xwe şîretên dayika xwe digrin û derî venakin.

\section{$\underline{\text { Mirin }}$}

Ev motîf jî di indeksê da bi tîpa Eyê hatiyê diyarkirin. Her du çîrok jî bi mirina gur diqede. Li vir mirin ne tene mirina gure mirina nebaşîye ye. Çîrok, peyama binketî û mirina xirabî û serketina paqijî û başiyê di jiyanê dedide. Her du çîrok jî wekî çîrokên din bi mirinekî diqede bi vê mirinê jî encamek baş dertê holê.

\section{$\underline{\text { Derasayî }}$}

Ev motîf jî di indeksê de bi tîpa Fyê hatiye diyarkirin. Derasayiyên her du çîrokan eve ku dema gur karikan dixwe û dayîka wan tê û wanxelas dike tiştekbi karikan nabe. Ev jî derasayîyeke. Dîsa di çîroka Elmanî de piştîxelas kirina karikan dayîka wan zikê gur tije kevir dike lê gur ji vê namire ev jî derasayîyeke.

Li gorî Ramazan Pertev, ketina zikê gur ji bo zarokan tê wateya daxwaziya ji nû ve ketina zikê dê jî. Xwesteka vegera zikê dayik heye. Lê di çîrokê de zarok ketine nava zikekî 
biyanî. Ev jî nîşanê me dide ku çîqas bixwazin jî nema vedigerin zikê dayikên xwe, divê zarok vê rastiyê êdî qebûl bikin. (Pertev, 2009:130)

\section{Biaqil û Xêvok}

Ev motîf di îndeksê de bi tîpa Jyê hatiye diyarkirin. Di Çîroka kurdiya Kurmancî de pêşî karik biaqiltî tevdigerin rengê lingê dayîka xwe ji gur re nabêjin. Çîroka Elmanî de jî bizin biaqiltî tevdigere û şuna karikan zikê gur bi keviran tije dike. Piştî şîyar bûnê gur, nizane di zikê wî de kevir heye ev jî xêvokatî ya gur e.

\section{Ezmûn}

Ev motîf jî di indeksê da bi tîpa Hyêhatiye diyarkirin. Di her du çîrokan de jî karik du caranji ezmuna gur derbas dibin. Di vê ezmunê de bersiva rast rengê linga dayika wan e. Dema dayik biçe çêrê şîret li wan dike ku dayîka xwe bi linge wê nas bikin. Gur di her du ezmunan de jî wan diceribîne. Diher duyan de jî karik bi serkeftî derbas dibin lê di ezmuna sisêyan de gur wan dixapîne.

\section{$\underline{\text { Xapandin }}$}

Ev motîf jî bi tîpa Kyê dilîsteyê da cî digre. Buyera her du çîrokan jî li ser xapandina karikan hatiye avakirin. Armanca gur ew e ku karikan bixapîne û her duyan jî ango her heftan jî bixwe. Gur ji bo xapandinê dixwaze xwe bişibîne mîna dayîka karikan. Di her du çîrokan de jî gur ji bo xapandinê peşîyê dengê xwe zelal dike. Dema bizin ji dengê jî bawer nebûn diçe rengê lingê xwe dişîbîne lingê dayîka wan ku wan bixapîne. Di dawîyê de bizin bawer dikin ku gur dayîka wan e û dixapin.

Di çîroka Hedlîlik û Bedlîlik dejî gur bi karikan dixape. Dema karik fêm dikin ku gur e, rengê linga dayika xwe xelet dibejin kubila gur bixape.

\section{Sihûd û Qeder}

Ev motîf jî bi tîpa Nyê hatiye diyarkirin. Dema bizin dibîne ku karikên wê tinene li wan digere. Di her du çîrokan da jî bizin gelek bi sihûde ku rasterast gur derdikeve pêşîya wê. Dîsa gelek bi sihude ku gur raza ye. Heya karik rizgar dibin jî ji xew ranabe. Di her du çîrokan de jî gur bi şanse ku sira navbera karik û bizin da heye fêm dike. Sira wan rengê linga dayîka wan bû lê gur bi devê karikan ev sira wan hîn bû û karikbi dest xistin.

\section{$\underline{\text { Xelat û Ceza }}$}

Ev motîf jî bi tîpa Qyê hatiyediyarkirin. Di her du çîrokan de ji xelat tine ye. Lê cezaya gur heye. Ceza ya gur jî mirine. 


\section{Qerf (Mîzah)}

Ev motîf jî bi tîpa Xyê hatiyediyarkirin. Her du çîrokan de jî motîfên qerfî̀ hene. Lê ya Kurdî de pirtir e. Di çîroka Elmanî de li dawîya çîrokê dema gur dibîne ku zike wî tije kevir e matmayî dibîne. Ev rewşa gur ji zarokan re bi mizahî tê. Di çîroka Kurdî de jî motîfa qerfê li çend ciha derbas dibe. Varyanta Şengê û Pêngê da Qadiyê wan diranê gur dikşîne û cihê dirana gur da dendikê kundiran dixe. Dîsa di heman varyantê da gur ji bo Qazî bixapîne û bireve nav tûrikê tije tirr û fisan dike.

Di her dû çîrokan de jî her çîqas mirinek dijwar be jî û ne li gorî zarokan be jî bi riya van mîzahan mirina dijwar bala zarokan nakşîne. "lê eger beranberî tirsê balkişîn li ser henek û pêkenîkan be, hingê tirs sivik dibe î ji holê radibe." (Pertev, 2009:117)

\section{$\underline{\text { Komên Motîfên Curbecur }}$}

Ev motîf jî bi tîpa Z.yê hatiyediyar kirin. Di her du çîrokan de jî hejmarên formel hene. Hejmarên formel wekî; 2, 3,7, 40 tê zanîn (Alptekîn, 1997:390). Hejmara karikan her çiqas cuda be jî wekî hejmara formel hejmara wan hatiye diyarkirin. Di çîroka Elmanî de hejmara formel ya 7, diKurdî de jî hejmara formel ya 2 hatiye bikaranîn.

\section{Motîfên ji hev cuda}

Di binê vê serenavê de em ê li ser motîfên ji hev cuda rawestin. Heya vêdê em di her du çîrokan de li ser motîfên hevpar sekinîn. Lê ji bil van, çîrokên bi Elmanî û bi Kurdî Hedlîlik û Bedlîlik da varyantên wê wekî Şengê û Pengê, Xezalok û Delalok û Heblûlik û Ceblûlik- de motîfên ji hev cuda hene.

\section{$\underline{\text { Civat }}$}

Ev motîf jî bi tîpa Pyê di lîsteyê de hatiyediyarkirin. Di varyanta Xezalok û Delalok û Heblûlik û Ceblûlik de dema bizin diçe cem gur ji wî re dibêje te karikên min xwarin lê gur înkar dike. Bi hev nakin û diçin cem "Mela" anjî "Qazî". Çûndina wan cem mela an jî qazî pergala civaka kurdan nîşanê me dike ku Kurd pirsgirêkên xwe çawa çareser dikin tîne ber çavan.

\section{$\underline{\mathrm{Ol}}$}

Ev motîf jî bi tîpa Vyê hatiyediyarkirin. Di varyanta "Xezalok û Delalok" û "Heblûlik û Ceblûlik" da wek karakterekî alîkar; di Xezalok û Delalok de Qazî, Heblûlik û Ceblûlik da jî Mela heye. Her du jî peywirdarên ola Îslamê ne. Ev çîrok jî nîşan didin ku bandora Îslamê di nav çîrokên Kurdan de jî heye. 


\section{ENCAM}

Me bi riya motifan ve jî dît ku, dema baş bê lêkolînkirin kereseyên wekî zimên, çand, dîrok hwd. ên di nava çîrokên Kurdî de veşartî ne derdikevin holê. Ji ber ku çanda devkî ya kurdan tu car wenda nebûye û xwe gihandiye heya îro bi riya çîrokan lêkolîner ji bil zimanekî xweş û zelal dikarin derhêqê Kurdan de gelek agahî wergirin.

Van taybetmendîyên ku me li jorê diyar kirin gerdûnbûna çîrokan xira nake heta dewlementir dike. Çîrok xwe bi welatan sînor nekiriye ji sînoran derbas bûye, bûye mala hemû mirovahiyê. Li her derê cîhanê her dem başî, paqijî, qencitî, pîroz kiriye; nebaşî, xirabî, çavnebarî yê jî qebul nekiriye.

Ji gotarê diyar bu ku çîrokeke bi Kurdî û çîroka ku ji alî birayên Grimm ve li Elmanyayê hatiye berhevkirin ji alî gelek motîfan ve dişibin hev. Di pirtûka Grimms Märchen International de navê heft welatan derbas dike ku hin çîrokên li wir û çîrokên Grîmm dişibin hev. (Coşan, 2001:7). Nava wan de çîrokên Kurdî tûne ne. Ji ber vê qasê xebatên zanistî weki berawirdkirina çîrokên bi Kurdî û yên birayên grîmm û çîrokên li welatên din divê zêde bibin.

Wekî gotina dawî em dikarin bibêjin ku her çiqas ji alî çîrokan ve çanda gelê kurd dewlemend be jî mixabin li ser çîrok, berhemên devkî xebatên zanistî gelek kêm in. Li ser çanda Kurdan a devkî ji alî lêkolînêran ve xebatên zanîstî li Rusyayê û li deverên din hatiye kirin. Li Türkiyeyê ji bil çend mînakan xebat ji sînora komkirin û ji antolojîya çîrokan derbas nebûye. Bê guman sedemen wê yên dîrokî û erdnigarîye hene. Lê bes edî ev xebat divê ji alî zanistî ve zêde bibin. Em bawer in dema xebatên li ser çîrokan were kirin ev dewlemendî dê zêdetir derkeve holê. Îro gelek çîrok ji bo vê xebatê benda me ne.

\section{ÇAVKANî}

Alakom, R. (2002). Folklor û Jinên Kurd. Stockholm: Weşanên Nefelê.

Alptekin, A. B. (1997). Halk Hikâyelerinin Motif Yapısı. Ankara: Weşanên Akçağê.

Aykanat, T. (2013). Grimm Masaları ve Klâsik Aşk Mesnevileri Üzerine Motiflerarası Bir Karş1laştırma. The Journal of Academic Social Science Studies, Volume 6 Issue 5, pp. 165-198.

Akyol, H. (2010). Kew û Kewê. Stênbol: Weşanên Do.

Akyol, H. Heblûlik û Ceblûlik. Herem Amed, Hazro, Nehatiye Weşandin

Akyol, H. Şengê û Pengê, Herem-Amed, Nehatiye Weşandin.

Bedirxan, C. A. (2009). Ferheng. Kurdî-Kurdî, Stenbol: Weşanên Avestayê.

Bozarslan, M. E. (1999). Mîr Zoro, Meselokên Lawiran, Cilt-1, Stenbol: Weşanên Deng.

Coşan, L. (2001). Sınırları Aşan Bir Masal. Ankara Üniversitesi Dil Dergisi. Language Journal. Sayl: 103. Ankara Üniversitesi Basımevi.

Izady, M. R. (1992). The Kurds: A Concise Handbook. Crane Russak, USA

Farqini, Z. (2007). Ferheng. İstanbul: Weşanên Enstîtuya Kurdî ya Stenbolê. 
Grimm J. \& Grimm W. (1999). Grimm Masallar (Kinder-Und Hausmarchen), c.II, Cumhuriyet Gazatesi, Dünya Klasikleri Dizisi.

Mukriyanî, G. (2010). Ferhengî Kurdistan, Kurdî-Kurdî. Weşanên Enstîtuya Kurdî ya Amedê, Amed.

Oğuz, M. Ö. (2010). Türkiyede Mit ve Masal Çalışmaları veya Bir Olumsuzlama ve Tek Tipleştirme Öyküsü. Millî Folklor Dergisi, Yıl 22, Sayı 85.

Pertev, R. (2009). Zarok û Çîrok. Stenbol: Weşanên Dozê

Ronahî, M. (2009). Kovara W. Weşana Enstîtuya Kurdî ya Amed ê. Hejmar:25.

Saadallah, S. (2010). Ferhanga Îngilîzî-Kurdi ya Selahadin. Enstîtuya Kurdi ya Parîsê, Stenbol: Weşanên Avesta.

Sakaoglu, S. (1999). Masal Arastırmaları. Ankara: Weşanên Akçağê.

Yavuz H. M. (2002). Masallar ve Eğitsel İşlevleri. Ankara: Weşanên T.C. Kültür Bakanliğiyê.

Yıldırım, K; Pertev, R. \& Aslan, M. (2013). Ji Destpêkê Heta Niha Folklora Kurdî. Weşanên Mardin Artuklu Üniversitesi, Türkiye'de Yaşayan Diller Enstitüsüyê, İstanbul.

http://www.ruthenia.ru/folklore/thompson/ -dîroka lênêrînê 05/08/2015-

http://e-weje.com/birayen-grimm-u-ciroka-gur-u-heft-karik/ －dîroka lênêrînê 08/08/2015- 